University of Alaska Southeast

From the ScholarWorks@UA collection of Andrzej Piotrowski

April 2, 2019

\title{
Proof without Words: On Sums of Squares and Triangles
} By Andrzej Piotrowski

\section{Author Post-Print}

Originally published in: Andrzej Piotrowski (2018). Proof without Words: On Sums of Squares and Triangles, Mathematics Magazine, 91:1, 42, DOI: 10.1080/0025570X.2018.1404885

\section{\scholarWorks@UA}

Available at: https://scholarworks.alaska.edu/handle/11122/10024 


\section{Proof without Words: On Sums of Squares and Triangles}

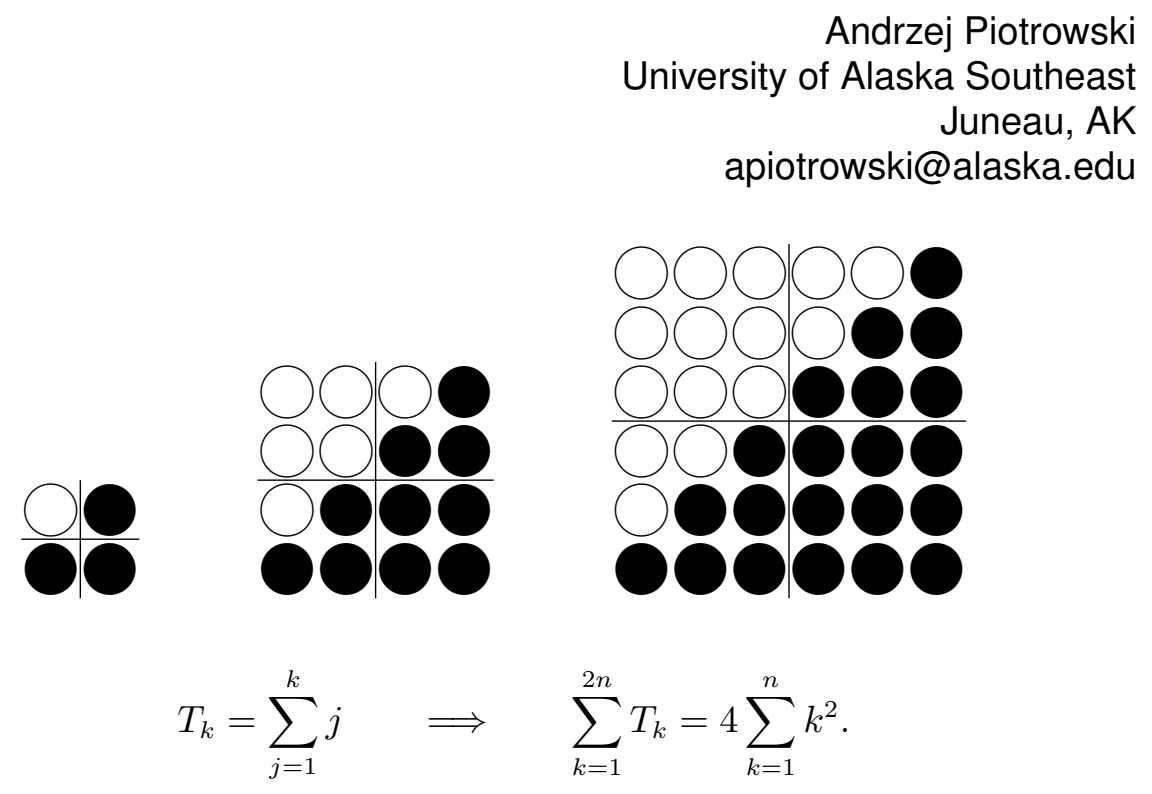

Remarks: If the diagram above is extended to contain the odd squares too, then it becomes clear that $\sum_{k=1}^{n} k^{2}=\sum_{k=1}^{n} T_{k}+\sum_{k=1}^{n-1} T_{k}$, which can also be derived from the results given in either of the PWW [4] or [5]. Thus,

$$
\sum_{k=1}^{2 n} T_{k}=4\left(\sum_{k=1}^{n} T_{k}+\sum_{k=1}^{n-1} T_{k}\right)=4 T_{n}+8 \sum_{k=1}^{n-1} T_{k},
$$

which can also be derived by summing the squares of the even integers using the result given in the PWW [2] and the definition of $T_{n}$. Finally, the reader is invited to compare this to other PWW involving sums of squares and triangular numbers, especially [1] and $[\overline{3}]$.

\section{REFERENCES}

1. R. K. Guy, Identities for triangular numbers, in Proofs Without Words: Exercises in Visual Thinking, Vol. 1, Edited by R. B. Nelsen, Mathematical Association of America, Washington, DC, 1993. 104.

2. E. G. Landauer, Proof without words: Square of an even positive integer, Math. Mag. 58 no. 4 (1985) 236.

3. D. Logothetti, Proof without words: Alternating sums of squares, Math. Mag. 60 no. 5 (1987) 291.

4. R. Nelsen, Proof without words: Alternating sums of triangular numbers, Math. Mag. 68 no. 4 (1995) 284.

5. W. Page, Proof without Words: Count the Dots, Math. Mag. 55 no. 2 (1982) 97.

Summary. We visually display a relationship between sums of squares and the sum of an even number of triangular numbers. Connections to some PWW appearing in the literature are briefly discussed.

ANDRZEJ PIOTROWSKI (MR Author ID: 1036554) received his B.S. and M.S. degrees from the University of New Hampshire and his Ph.D. degree from the University of Hawai' $i$ at Mānoa. He is currently an Associate Professor of Mathematics at the University of Alaska Southeast in Juneau, AK. 